\title{
СОЗДАНИЕ СИСТЕМЫ УПРАВЛЕНИЯ РИСКАМИ И БАЗЫ ИНЦИДЕНТОВ В МЕДИЦИНСКОЙ ОРГАНИЗАЦИИ
}

\author{
Идрисова Салтанат Садыровна \\ докторант \\ КазНУ им. Аль-Фараби
}

\begin{abstract}
Аннотация: Менеджмент медицинской организации должен быть направлен на создание стратегической ценности - безопасности пациента как индикатора качества медицинской помощи. Для превентивного менеджмента необходима система управления рисками, основанная на анализе базы инцидентов, систематизированных на региональном и национальном уровнях.
\end{abstract}

Ключевые слова: Инцидент, управление рисками, учет и анализ, база, стандарт, качество медицинской помощи, менеджмент.

\section{CREATING AN INCIDENT DATABASE IN A RISK MANAGEMENT SYSTEM A MEDICAL ORGANIZATION}

\section{Idrissova Saltanat Sadyrovna}

\begin{abstract}
The management of a medical organization should be aimed at creating a strategic value - patient safety as an indicator of the quality of medical care. Preventive management requires a risk management system based on the analysis of the database of incidents systematized at the regional and national levels.

Key words: Incident, risk management, accounting and analysis, database, standard, quality of medical care, management.

Мы стремимся сделать медицинскую практику настолько безопасной, насколько это возможно. Это способствует продвижению качества медицинской помощи, но при этом, нам необходимо иметь способы сдерживания и управления неизбежными рисками, которые при этом возникают. Максимально возможное качество медицинского обслуживания всегда должно включать пользу для пациента, так как отсутствие безопасности отрицательно влияет на результат лечения.
\end{abstract}


Безопасность - это «состояние защиты от опасностей, риска или травмы, или их маловероятного возникновения». Риск означает предупреждение о возможном причинении вреда и описывает потенциал/возможность/ вероятность угрозы состоянию безопасности [1].

Система управления рисками в медицинской организации (MO) позволяет повысить безопасность пациентов, а также уменьшить негативные последствия инцидентов, количество неудовлетворенных пациентов, судебные иски, расходы на диагностику и лечение.

Управление рисками или риск - менеджмент - это процесс принятия и выполнения управленческих решений, который преследует цель снижения вероятности возникновения неблагоприятного результата и минимизация возможных потерь, вызванных какой - либо деятельностью [2].

В Республике Казахстан в здравоохранении законодательно регламентирована необходимость внутреннего контроля $\mathrm{c}$ рискориентированным подходом. Но МО вынуждены проводить политику управления рисками без соответствующего методологического сопровождения. Также введение требования в Закон Республики Казахстан «О государственном имуществе» создания служб внутреннего аудита в подчинении Наблюдательных советов привело к смешению их функций с работой служб качества или поддержки пациентов, имевшихся ранее в структурах МО. В то же время, действующее обязательное социальное медицинское страхование (OCMC) требует изменений в работе данных служб, а именно, усиления их работы в направлении экспертизы медицинской помощи и поддержки пациентов.

С внедрением медицинского страхования финансирование отрасли здравоохранения значительно возросло. Если в 2019 году бюджет сферы здравоохранения составлял около 1 трлн. тенге, то в 2020 году увеличился до 1,7 трлн. тенге, а в 2021 году - до 2,2 трлн. тенге, из них 64\% предусмотрено на оплату медицинских услуг по гарантированному объему бесплатной медицинской помощи (ГОБМП). В МО службы качества или поддержки пациентов сейчас заняты контролем соблюдения стандартов оказания медицинской помощи и распределением пациентов по кодам заболеваний для выполнения плана по договорам с НАО «Фонд социального медицинского страхования» по источникам финансирования - ГОБМП и ОСМС. Планировать годовые объемы медицинской помощи и оказание медицинских услуг разным категориям населения затруднительно и вызывают риск недостатка у МО 
финансовых средств в рамках договоров ГОБМП или ОСМС. Это приводит к разрыву клинического процесса, нарушению медицинского производственного процесса, и способствует медицинских работников прибегать к «искусственному», ошибочному кодированию, когда код определяется не заболеванием, а наличием принадлежности к пакету медицинской помощи [3].

На сегодня вопрос управления рисками остается в введении Наблюдательного совета (высший орган МО) и руководства МО. Политика управления рисками должна разрабатываться в МО в соответствии со стандартом Федерации Европейских ассоциаций риск - менеджеров (Federation of European Risk Management Association (FERMA)). Стандарт управления рисками (Risk Management Standard) по признанию ряда западных специалистов, является «лучшей практикой», относительно которой организации могут оценивать самих себя [4].

В отчете, опубликованном в 2021 году FERMA и глобальной консалтинговой фирмой McKinsey, приводятся доказательства важности менеджеров по рискам и страхованию для устойчивости их организаций. Опрос показал, что более $90 \%$ реципиентов согласны с тем, что глобальная пандемия сделала управление рисками и устойчивость более важными для их организаций. Более $60 \%$ участников признают устойчивость главным приоритетом или очень важным фактором при принятии стратегических решений [5].

В мире почти три четверти опрошенных риск - менеджеров видят очевидную необходимость как в улучшении культуры управления рисками, так и в более активной интеграции устойчивости в стратегии своих организаций.

В МО, внедряющей систему управления рисками в соответствии со стандартом FERMA, выделяют следующие риски:

1. Финансовые (процентная ставка, курс валют, объемы помощи);

2. Стратегические (конкуренция, изменения потребительского рынка, отраслевые изменения);

3. Операционные (законодательство, культура, состав совета директоров);

4. Опасности (договора, естественные опасности, поставщики, окружающая среда).

Вышеперечисленные риски можно отнести к внешним факторам. Внешние факторы одинаково воздействуют на все МО с учетом их специфики. 
К внутренним факторам относят ликвидность средств, денежный поток, исследования, интеллектуальный капитал, коммерческую службу, медицинские кадры, имущество, продукцию и услуги, бухгалтерский учет, информационное обеспечение. Внутренние факторы специфичны и зависят, в основном, от уровня менеджмента в МО. Для оценки рисков проводится анализ инцидентов, происходящих в МО. Для уменьшения рисков в МО предлагаю ввести обязательный сбор инцидентов в базе каждой $\mathrm{MO}$ с последующей их унификацией и централизацией по всей стране.

Кроме того, в Казахстане для определения неблагоприятного события в Кодекс «О здоровье народа и системе здравоохранения» введен термин «медицинский инцидент» [6]. Введение данного дефиниция в Кодекс явилось важным событием для развития системы управления рисками и, соответственно, страхования профессиональной ответственности медицинских работников. Таким образом, в нашей стране, в правовом поле решен вопрос с определением нежелательных медицинских явлений, под которым понимается медицинский инцидент.

Каждая страна разработала свою собственную систему сообщений о нежелательных медицинских явлениях, в нашем случае, инцидентах. Сообщения об инцидентах могут быть обязательными или добровольными, с целью обучения или подотчетности.

С учетом международного опыта в нашей стране с 2020 года начато создание баз медицинских инцидентов на основе самоанализа, выявляемых MO. Приказом министра здравоохранения от 22 октября 2020 года «Об утверждении правил определения случаев (событий) медицинского инцидента, их учета и анализа» определена служба поддержки пациента и внутренней экспертизы [7]. Правилами определен порядок информирования о медицинском инциденте на сайте организации на основе самоанализа. Опубликованные на сайте МО медицинские инциденты в последующем должны анализироваться местными органами государственного управления, государственными органами в сферах санитарно - эпидемиологического благополучия, обращения лекарственных средств и медицинских изделий, уполномоченным органом в области здравоохранения.

В соответствии с требованиями национальной аккредитации в МO внедряются программы по управлению рисками. Согласно международному стандарту ISO 31000:2018 Менеджмент рисков, МО внедряющая систему управления рисками в соответствии со своей миссией может определить 
основной ценностью безопасность пациента как критерий качества медицинской помощи и развивать культуру безопасности. Для достижения этих целей требуется наладить:

1. получение сообщений об инцидентах, в том числе, потенциальных и в режиме реального времени;

2. снижение рисков для пациентов, персонала и организации в целом;

3. определение слабых сторон организации;

4. определение областей для улучшения деятельности организации.

Для системы управления рисками необходимо расширить определение инцидента по всем аспектам деятельности MO на примере изучения международного опыта работы с инцидентами.

В случае своевременности рассмотрения и принятия предупреждающих действий руководством, признается, что половина инцидентов являются предотвратимыми событиями, поэтому очень важно анализировать как произошедшие, так и потенциальные инциденты. Для этого требуется проведение регламентации и упорядочения процессов по сбору данных, их свода и анализа компетентным государственным органом. Действующие Правила учета и анализа медицинских инцидентов являются основой для создания баз и построения системы управления рисками в здравоохранении Казахстана. Но для системы управления рисками необходимо расширение данной базы с включением в нее всех инцидентов, связанных со всеми рисками: финансовыми, операционными, информационными и др. По результатам анализа данных общей базы инцидентов следует проводить выявление и оценку всех рисков, которые могут использоваться для расчета тарифов для страхования профессиональных рисков. В этом случае система управления рисками также будет способствовать развитию системы страхования профессиональной ответственности медицинских работников.

Развитие системы управления рисками в МО способно обеспечить устойчивость МО и дать дополнительные возможности по обеспечению безопасности в процессе оказания медицинской помощи, стратегического прогнозирования, планирования сценариев и стресс-тестирования. 


\section{Список литературы}

1. Ральф Эдвардс, И. Линдквист, Мари. Что такое «риск и безопасность в медицине?» Гётеборг, Швеция,Международный журнал рисков и безопасности в медицине, 23 апреля 2021, с. 1-2.

2. Н.В.Кондратова. Как управлять рисками в медицинской организации Электронный журнал «Здравоохранение. Журнал для управления медицинской организацией». https://e.zdravohrana.ru/476592, №7, июль 2016 г.

3. Проект консультативного документа регуляторной политики проекта Закона Республики Казахстан «О внесении изменений и дополнений в некоторые законодательные акты РК по вопросам обязательного социального медицинского страхования», https://www.gov.kz/memleket/entities/dsm/documen ts/details/253077?lang=ru

4. Стандарт FERMA https://studme.org/34776/finansy/standart_ferma https://www.ferma.eu/publications/

5. Отчет FERMA: Роль управления рисками в корпоративной устойчивости https://www.ferma.eu/publication/the-role-of-risk-management-incorporate-resilience/.

6. Кодекс Республики Казахстан «О здоровье народа и системе здравоохранения» от 7 июля 2020 года № 360-VI 3.

7. Приказ министра здравоохранения РК «Об утверждении правил определения случаев (событий) медицинского инцидента, их учета и анализа» от 22 октября 2020 года. 